\title{
CCR9 in cancer: oncogenic role and therapeutic targeting
}

\author{
Zhenbo Tu${ }^{\dagger}$, Ruijing Xiao ${ }^{\dagger}$, Jie Xiong, Kingsley M. Tembo, Xinzhou Deng, Meng Xiong, Pan Liu, Meng Wang \\ and Qiuping Zhang*
}

\begin{abstract}
Cancer is currently one of the leading causes of death worldwide and is one of the most challenging major public health problems. The main challenges faced by clinicians in the management and treatment of cancer mainly arise from difficulties in early diagnosis and the emergence of tumor chemoresistance and metastasis. The structures of chemokine receptor 9 (CCR9) and its specific ligand chemokine ligand 25 (CCL25) have been elucidated, and, interestingly, a number of studies have demonstrated that CCR9 is a potential tumor biomarker in diagnosis and therapy, as it has been found to be highly expressed in a wide range of cancers. This expression pattern suggests that CCR9 may participate in many important biological activities involved in cancer progression. Researchers have shown that CCR9 that has been activated by its specific ligand CCL25 can interact with many signaling pathways, especially those involved in tumor chemoresistance and metastasis. This review, therefore, focuses on CCR9 induction activity and summarizes what is currently known regarding its role in cancers and its potential application in tumor-targeted therapy.
\end{abstract}

Keywords: CCR9, CCL25, Biomarker, Chemoresistance, Metastasis, Targeting therapy

\section{Background}

Chemokines are a class of small proteins with molecular weights of approximately 8-14 $\mathrm{kDa}$ that, once combined with their homologous receptors, can activate and chemoattract leukocytes. Chemokine receptors are G proteincoupled receptors with seven transmembrane domains. Chemokines and their receptors play vital roles in the migration of thymocytes and maturation in normal and inflammatory environments. At the same time, they have great potential for use in tumor-targeted therapy $[1,2]$ in which, cancer-related chemokines could promote tumor proliferation, angiogenesis, and chemoresistance [3-5]. In the past decade, chemokine ligand 25 (CCL25)/chemokine receptor 9 (CCR9) have been found in a wide variety of tumors and have been associated with tumor chemoresistance and metastasis. This review will examine the expression of CCR9 in cancer, recent insights into the mechanisms of CCL25/CCR9 that are involved in tumor

\footnotetext{
*Correspondence: qpzhang@whu.edu.cn

${ }^{\dagger}$ Equal contributors

Department of Immunology, School of Basic Medical Science, Wuhan University, Wuhan 430071, China
}

chemoresistance and metastasis, and the potential application of CCR9-based targeted therapy.

\section{Structure and characteristics \\ CCR9}

CCR9 is located on chromosome 3p21.31 and belongs to the $\beta$-chemokine receptor family. It consists of transcripts A (369 amino acids, $42 \mathrm{kDa}$ ) and B (357 amino acids, $40.8 \mathrm{kDa}$ ). The molecular structure of CCR9 (44 to 241 amino acids) is shown in Fig. 1a. CCR9 is mainly distributed in immature $\mathrm{T}$ lymphocytes and on the surface of intestinal cells, and it plays a role in T lymphocyte development and tissue-specific homing when bound to its specific ligand.

\section{CCL25}

CCL25, also known as thymus-expressed chemokine (TECK), belongs to the CC chemokine family and is the specific ligand for CCR9. CCL25 is located on chromosome 19p13.2 and consists of isotype 1 (150 amino acids, $16.6 \mathrm{kDa})$, isotype $2(84$ amino acids, $9.5 \mathrm{kDa})$, and isotype 3 (149 amino acids, $16.5 \mathrm{kDa})$. The molecular structure of CCL25 (28 to 93 amino acids) is shown 


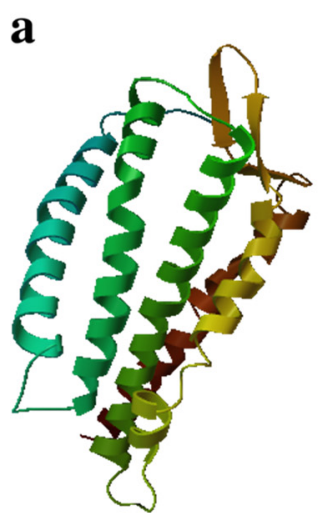

CCR9 b

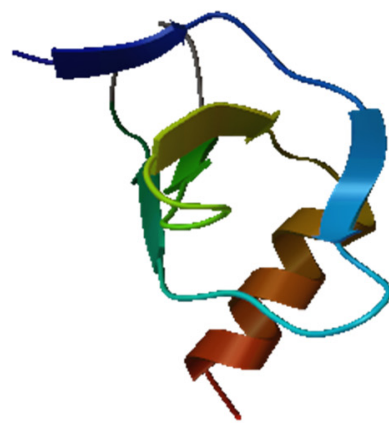

CCL25 c

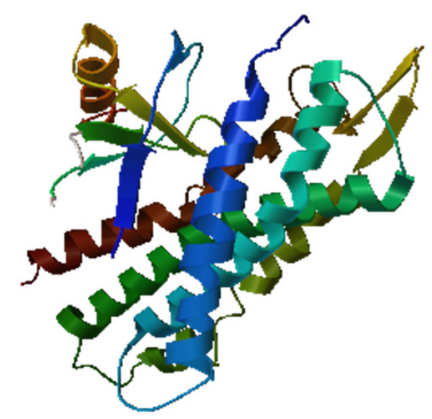

The simulation of CCR9 and CCL25

Fig. 1 The structures of CCR9 and CCL25. The molecular structures of CCR9 (a) and CCL25 (b) from the UniProt web site (http:// www.proteinmodelportal.org/query/uniprot). The simulated interaction of CCL25 and CCR9 was performed by MGLTools 1.5.6 software based on the structures of CCR9 and CCL25 (c)

in Fig. 1b. The simulated interaction between CCL25 and CCR9 is shown in Fig. 1c.

\section{The expression of CCR9 in cancer}

Several studies have found that CCR9 is highly expressed in a variety of cancers (Table 1). These studies have confirmed that various factors lead to the upregulation of CCR9, such as TNF- $\alpha$, which promotes CCR9 expression in human breast cancer MCF-7 cells [6], Notch signaling has been observed to induce CCR9 upregulation, which plays a vital role in $\mathrm{T}$-lineage acute lymphoblastic leukemia (T-ALL) [7]. Moreover, we are finding that certain non-coding RNAs, such as miRNA and lncRNA, can mediate the expression of CCR9 and further affect its biological function.

\section{The pathway of CCL25/CCR9 in cancer}

With recent statistics showing that one in four deaths in the USA is due to cancer [8]. Cancer mortality remains high, while the number of cancer survivors continues to

Table 1 The expression of CCR9 in cancer patients

\begin{tabular}{|c|c|c|c|c|}
\hline Tumors & Cell type & Methods & Expression & References \\
\hline T-ALL & $\operatorname{PBMCs}(n=21)$ & FCM & $91.9 \%$ & {$[25]$} \\
\hline Melanoma & Circulating tumor cells $(n=21)$ & FCM & $57 \%$ & [58] \\
\hline Melanoma & Primary specimens $(n=32)$ & $\mathrm{IHC}$ & $69.7 \%$ & [59] \\
\hline Melanoma metastasis & Small intestinal metastases $(n=102)$ & QPCR & $86 \%$ & {$[30]$} \\
\hline Mediastinal large B cell lymphomas & Lymphoid tissue $(n=22)$ & $\| \mathrm{HC}$ & $90.9 \%^{a}$ & {$[60]$} \\
\hline Large B cell lymphoma & Gastric extranodal diffuse lymphoma $(n=10)$ & $\mathrm{HC}$ & $58.33 \%$ & {$[61]$} \\
\hline Large B cell lymphoma & Gastrointestinal lymphoma $(n=41)$ & $\mathrm{HC}$ & $66 \%^{b}$ & {$[62]$} \\
\hline Ovarian cancer & Cancer tissues $(n=43)$ & $\mathrm{HC}$ & Significantly higher & {$[11]$} \\
\hline Lung cancer & Lung biopsies $(n=50)$ & WB & $1.2^{c}$ & {$[63]$} \\
\hline Hepatocellular carcinoma & Cancer tissues $(n=240)$ & $I H C$ & $55.8 \%$ & {$[9]$} \\
\hline \multirow[t]{2}{*}{ Breast cancer } & Moderately differentiated cancer tissues $(n=18)$ & $\mathrm{IHC}$ & $50 \%$ & [64] \\
\hline & Poorly differentiated cancer tissues $(n=18)$ & $H C$ & $>75 \%$ & \\
\hline Colon cancer & Adenomatous foci $(n=46)$ & $\| H C$ & $2.26 \pm 0.06^{d}$ & {$[65]$} \\
\hline Nasopharyngeal carcinoma & Carcinoma tissues $(n=42)$ & $\mathrm{HC}$ & $80.95 \%$ & {$[66]$} \\
\hline
\end{tabular}

FCM flow cytometry, PBMC peripheral blood mononuclear cell, QPCR quantitative polymerase chain reaction, IHC immunohistochemistry, WB western blot ${ }^{\text {a }}$ roportion of positive tumor cells $>50 \%(20 / 22)$

$\mathrm{b}^{+}$CCR9 staining

${ }^{c}$ Control tissue $(n=50), C C R 9 / \beta$-actin $<0.3$

${ }^{\mathrm{d}}$ Normal colon epithelium had a mean staining intensity of $1.60 \pm 0.04(n=55)$ 
increase. Some of the challenges faced by clinicians in the management and treatment of cancers include difficulties in diagnosing cancer in the early onset stages and the emergence of tumor chemoresistance and metastasis.

Recently, researchers have focused on CCR9 expression in selected cancers and on how CCR9 expression can be manipulated as a potential tumor biomarker in cancer diagnosis and treatment. The interaction of CCL25/CCR9 has been shown to activate many signaling pathways in cancer, especially those involved in tumor chemoresistance and metastasis. Therefore, in this review, we focus on CCR9 as a potential tumor biomarker and on how the CCL25/CCR9 pathway is involved in tumor chemoresistance and metastasis.

\section{CCR9 as a tumor biomarker}

CCR9 expression has been shown to be increased in various cancers, and CCR9 is specifically expressed in certain tissues. Studies have revealed that ectopic expression of CCR9 may be mediated by the downregulation of p21 and p27 and upregulation of cyclin D1 to enhance cell proliferation and tumorigenicity in hepatocellular carcinoma cells. Additionally, the ectopic expression of CCR9 has been shown to be an independent prognostic factor for the overall survival of hepatocellular carcinoma patients [9]. Other researchers have shown that the upregulation of CCR9 was associated with a poor response to infliximab, which is an anti-tumor necrosis factor- $\alpha$ (TNF- $\alpha)$ antibody drug used in psoriasis patients. Therefore, CCR9 expression can act as a novel prognostic marker and therapeutic target for hepatocellular carcinoma [9] and may be a useful biological marker of the clinical efficacy of infliximab therapy in psoriasis patients [10].

\section{CCL25/CCR9 induces tumor chemoresistance CCL25/CCR9 causes conformational change of PI3K dimers to activate PI3K/AKT pathway}

The interaction of CCL25/CCR9 can cause conformational changes that allow PI3K dimers to activate PI3K. Activated PI3K on the plasma membrane can produce a second messenger (PIP3) that binds with the intracellular AKT PH domain and phosphoinositide-dependent kinase (PDK) 1 to phosphorylate AKT at Thr308 and PDK2 to phosphorylate AKT at Ser473. Activated AKT can activate the phosphorylation of NF- $\mathrm{kB}$ or mTOR signaling molecules, or it can inhibit its downstream target protein, GSK-3 $\beta$, to mediate cancer proliferation and apoptosis [11-13]. Recent studies have shown that CCL25/CCR9, via activating the PI3K/AKT signaling pathway, mediated anti-apoptotic processes in lung cancer [12], induced etoposide resistance in prostate cancer [14], and induced cis-platinum resistance, which is dependent on PI3K and not FAK, in breast and ovarian cancer $[15,16]$.

\section{CCL25/CCR9 enhances the interaction of P-gp and ERM to increase drug efflux}

We found that CCL25/CCR9 involvement in the resistance of TNF- $\alpha$-induced apoptosis in T-ALL depends on Livin, thus suggesting that CCL25/CCR9 plays an anti-apoptotic role [17]. Furthermore, we obtained a multi-resistant T-ALL cell line, MOLT4/ DOX, which was derived from MOLT4 (which has a naturally high expression of CCR9) through doxorubicin dosing screening. Then, we investigated this multiresistant cell line and found that CCR9 induces resistance to chemotherapy drugs, which could be blocked by CCR9 antibodies. We confirmed that CCL25/CCR9 influences the interaction of $\mathrm{P}$-gp and the cytoskeleton protein ERM to increase P-gp efflux, thus mediating TALL tumor chemoresistance [18].

\section{CCL25/CCR9 mediates STAT signaling to weaken cytotoxic effect}

Tumor resistance to cytotoxic $\mathrm{T}$ lymphocytes mainly limits $\mathrm{T}$ cell tumor immunotherapy. Khandelwal and colleagues performed a siRNA rapid high-throughput screen and found that in T cells, STAT signaling pathways were mediated by CCR 9 and affected Th1 cytokine secretion to weaken the cytotoxic effect. Therefore, inhibiting CCR9 expression in vivo could significantly improve the effect of tumor-specific T cell-mediated immune therapy [19].

\section{CCL25/CCR9 activates $\beta$-catenin to induce tumor chemoresistance}

CCR9-mediated activation of $\beta$-catenin and the resulting downstream effects were effectively inhibited by blockade of the PI3K/AKT pathway. Further, $\beta$-catenin activation induced by CCR9 increased the expression of Cyclin E1, Cyclin D1, and E-Cadherin to increase the lethal dose of gemcitabine in pancreatic cancer, suggesting that CCR9/ $\beta$-catenin signaling enhances pancreatic cancer chemoresistance [20]. A diagram of the mechanism of CCR9-mediated tumor chemoresistance is shown in Fig. 2.

\section{CCL25/CCR9 induces tumor metastasis CCL25/CCR9 increases the expression of MMP2 and MMP9 to degrade collagen type IV}

The degradation of the extracellular matrix and basilar membrane is a key step in the process of cancer cell invasion and metastasis that mainly involves matrix metalloproteinases (MMPs). MMPs are proteolytic enzymes that are closely associated with tumor metastasis. Most MMPs contain an affiliate area to adjust the catalytic 


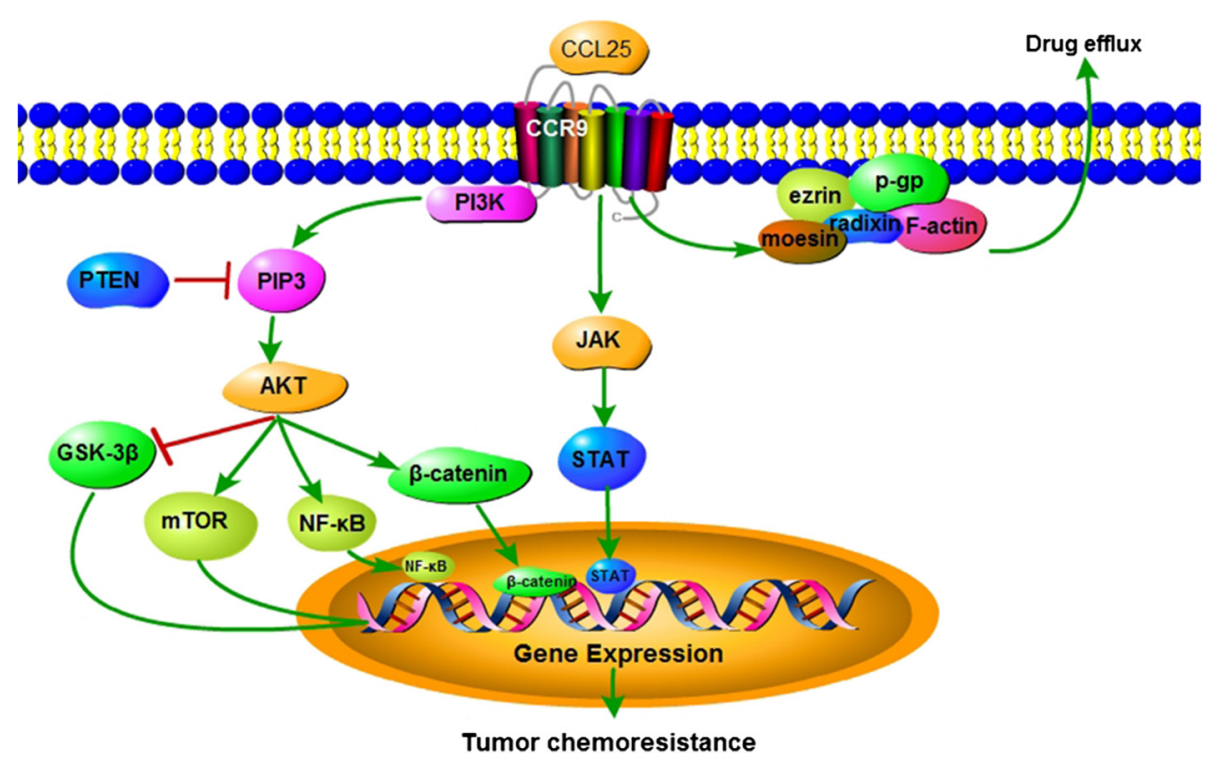

Fig. 2 Diagram summarizing the reviewed mechanisms by which CCR9 induces different aspects of tumor chemoresistance. The interaction of CCL25/CCR9 can induce tumor chemoresistance via the PI3K-AKT-(GSK-3 $\beta / m T O R / N F-K B / \beta$-catenin) and JAK-STAT pathways. The interactions between P-gp, ERM, and F-actin can induce tumor chemoresistance via the CCL25/CCR9 pathway

activity and identify the substrate, while others have affiliate areas that have no catalytic activity but can play a role in tumor progression. For example, MMP-2 and MMP-9 have three fibronectins, which repeatedly inserted in the catalytic area to connect the substrates gelatin, collagen, and laminin. Therefore, MMP-2 and MMP-9 can degrade collagen type IV, which is a major component of the basilar membrane. Studies have found that the interaction of CCL25/CCR9 can increase the expression of MMP-2 and MMP-9, which induce tumor metastasis in a variety of cancers, such as ovarian cancer [21], prostate cancer [22], non-small cell lung cancer [23], and endometriosis [24].

\section{CCL25/CCR9 induces cancer cells polarization and microvilli absorption}

Our previous study found that CCR9 is highly expressed in $\mathrm{CD}^{+} \mathrm{T}$ cells from T-ALL patients, with little or no expression in normal $\mathrm{T}$ cells. The chemotaxis and adhesion effects on leukemia cells were ablated when CCR9 was internalized on the T-ALL CD4 ${ }^{+} \mathrm{T}$ cells, which suggests that CCR9 is closely related to the infiltration and metastasis of leukemia cells [25]. Further studies showed that CCL25/CCR9 induces MOLT4 cell polarization and microvilli absorption to participate in leukemia infiltration and trafficking via the RhoA-ROCK-MLC and ezrin pathway [26, 27]. A diagram of the mechanism of CCR9-mediated tumor metastasis is shown in Fig. 3.

\section{Paracrine CCL25 induces tumor metastasis}

Most cancer cells upregulate CCR9 to mediate metastasis, and some cancers secrete CCL25 in a paracrine fashion; these cells include pancreatic cancer PSCs and PANC-1 cells, which then induce metastasis by binding the secreted CCL25 to CCR9 receptors in the nearby tissues [28]. The mechanism of metastasis remains unclear.

\section{CCR9 as a lymphocyte homing receptor}

Chemokine receptors can also act as homing receptors for chemotaxis-specific cell homing to specific positions. Studies have shown that CCR9 is highly expressed in melanoma skin lesions [29], and that melanoma cells are specifically targeted to the small intestine when CCL25/ CCR9 signaling is activated [30, 31]. In addition, CCR9 is highly expressed in adult lymphoblastic leukemia cells, and the $\mathrm{CD}^{+} \mathrm{T}$ cells that infiltrate the gastrointestinal tract show high CCR9 expression as detected by immunohistochemistry, suggesting that the infiltration of leukemia cells into the intestine is closely related to CCR9 expression in patients [32].

\section{CCL25/CCR9 inhibits the bioactivity of PTEN gene}

The expression of cytokines in the cancer microenvironment can affect the PTEN gene. It has been observed that CCR9-induced tumor proliferation and migration activity is increased with the loss of PTEN in T-ALL models, suggesting that PTEN loss can inhibit tumor 


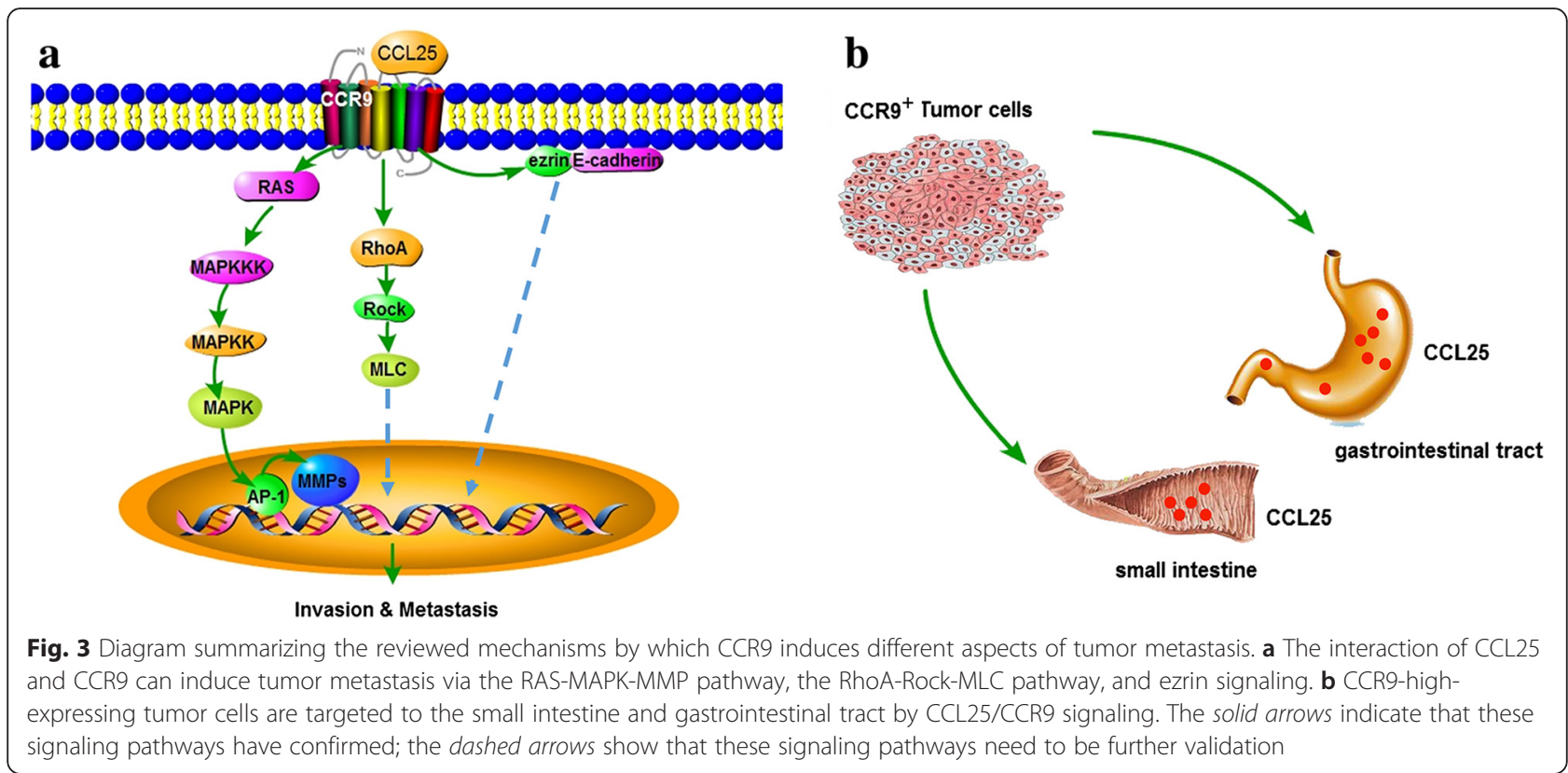

metastasis [33]. Therefore, the mechanisms of CCL25/ CCR9-induced tumor metastasis are complex and require further research.

The different signaling pathways of CCL25/CCR9 that are involved in cancer chemoresistance and metastasis are shown in Table 2, and a diagram of the mechanism of CCR9-mediated tumor chemoresistance and metastasis is shown in Fig. 4.

\section{Targeted therapy research}

When we identify a molecule that is highly expressed in cancer and rarely expressed in normal tissues, it is important to know whether there is clinical value to this information. Some researchers have developed an anti-CD19 monoclonal antibody with high killing activity against $\mathrm{B}$ cell malignancies, acute lymphoid leukemia, and B-ALL cells based on a specific B cell marker (CD19) [34-36]. Debra and colleagues found that anti-HuD-based immunotoxin therapy might be an effective alternative treatment for patients with small cell lung cancer and neuroblastoma because the $\mathrm{HuD}$ antigen is expressed in $100 \%$ of small cell lung cancer cells and in over $50 \%$ of neuroblastoma cells [37]. Presently, others and we found that CCR9 is highly expressed in various cancers (Table 1), and have focused on targeting therapy based on CCR9.

\section{CCR9 antibody}

A number of studies have developed chemokine receptor-specific monoclonal antibodies as potential targeted therapies based on the important roles of chemokines and their receptors, such as CXCR4 [38], CXCR5 [39], CCR4 [40], and CCR7 [41] in cancer. Chamorro and colleagues identified and developed a

Table 2 The signaling pathway of CCL25/CCR9 in cancer chemoresistance and metastasis

\begin{tabular}{lll}
\hline & Pathway & Reference \\
\hline Tumor chemoresistance & PI3K/AKT & Lung cancer [12], prostate cancer [14], breast cancer [15], ovarian cancer [16] \\
& P-gP/ERM/F-actin & T-ALL [17, 18] \\
& STAT & Breast cancer [19] \\
& B-catenin/cyclin & Pancreatic cancer [20] \\
MMPs & Ovarian cancer [21], prostate cancer [22], non-small cell lung cancer [23], endometriosis [24] \\
Tumor metastasis & RhoA-ROCK-MLC/ezrin & T-ALL [26, 27] \\
& Paracrine of chemokines & Pancreatic cancer [28] \\
& Lymphocyte homing & Melanoma [29, 31], lymphoblastic leukemia [32] \\
& PTEN signaling & T-ALL [33] \\
\hline
\end{tabular}




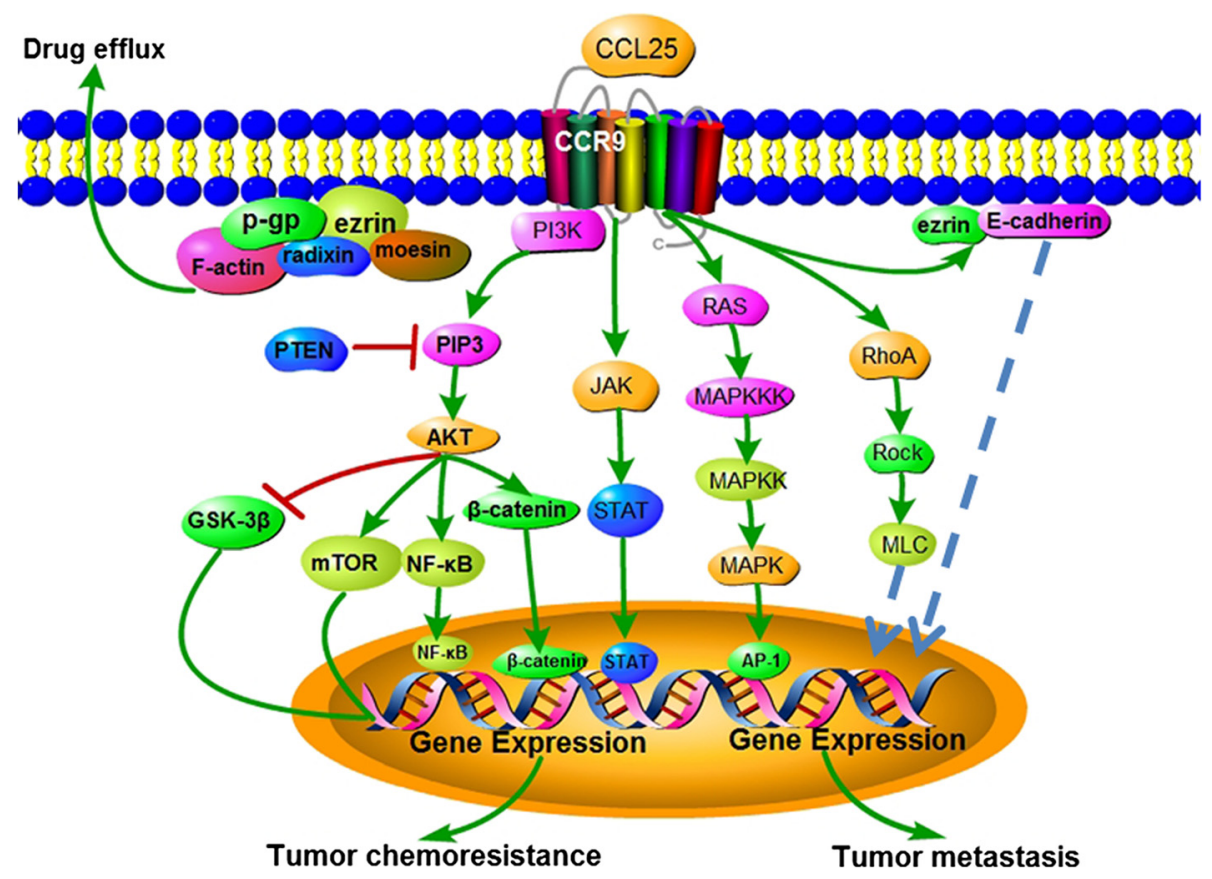

Fig. 4 Diagram summarizing the reviewed mechanisms by which CCR9 induces different aspects of tumor chemoresistance and metastasis. The solid arrows indicate that these signaling pathways have confirmed; the dashed arrows show that these signaling pathways need to be further validation

mouse anti-human CCR9 IgG2b monoclonal antibody (91R) that can recognize an epitope within the CCR9 $\mathrm{N}$-terminal domain and that inhibits the growth of subcutaneous xenografts in mice with an $85 \%$ reduction in tumor size compared with controls. Tumor reduction was consistent, and apoptotic cells and tumor necrotic areas increased as the number of proliferating cells decreased in 91R-treated mice [42].

\section{Immunotoxin}

Drug-targeted therapy is usually selective for specific systems, organs, tissues or cells, and this plays an important role in the area of the specific targeted treatment. Recently, targeted therapy has mainly included immunotoxins [43, 44], bispecific antibodies [45, 46], Nano-agents [47], ultrasound and microbubbles [48], and other specific inhibitors [49]. The CCR9-specific antibody has presented a challenge in terms of delivery to specific tissues due to its larger molecular weight, hence limiting its application. Most importantly, few antibodies are clinically useful as single agents because they do not efficiently kill cancer cells [50]. To further enhance the anti-tumor efficiency and reduce side effects, receptor-targeted therapy has been developed [51]. CCR9-based targeted therapy mainly involves an immunotoxin-CCL25 combination that has a small molecular weight and a high specificity. Its chemotactic ability to target cells makes it useful in the targeted therapy of $\mathrm{CCR} 9^{+}$malignant cancers with good prospects for application.

We previously developed a CCL25-PE38 fusion protein using genetic engineering. PE38 is a derivative of Pseudomonas exotoxin A (PE). PE38 is composed of domains II and III of PE; domain II (278 to $389 \mathrm{bp)} \mathrm{con-}$ tains a furin cleavage site, while domain III (430 to $638 \mathrm{bp}$ ) has ADP-ribosylating activity [52]. When the ligand binds with its specific receptor, the immunotoxin is internalized via the endolysosomal system to the Golgi apparatus and is further transported to the endoplasmic reticulum, where PE38 is activated through reduction of a disulfide bond and cleavage by the protease furin at a site that separates the Fv from the catalytic fragment of PE38. Subsequently, the activated PE38 translocate to the cytosol, where it ADP-ribosylates and inactivates elongation factor 2, an essential component of the translation apparatus, thus halting protein synthesis and eventually leading to cell death [53]. The mechanism of PE38 action is shown in Fig. 5 [54].

Our results demonstrated that CCL25-PE38 is able to specifically kill MOLT4 cells via induction of apoptosis. This result suggests that CCL25-PE38 could suppress the growth of CCR9-positive cancers, as CCR9-highexpressing human T-ALL cells underwent apoptosis when exposed to a PE38 toxin fused to a CCL25 ligand. However, it can be said that it cannot completely 


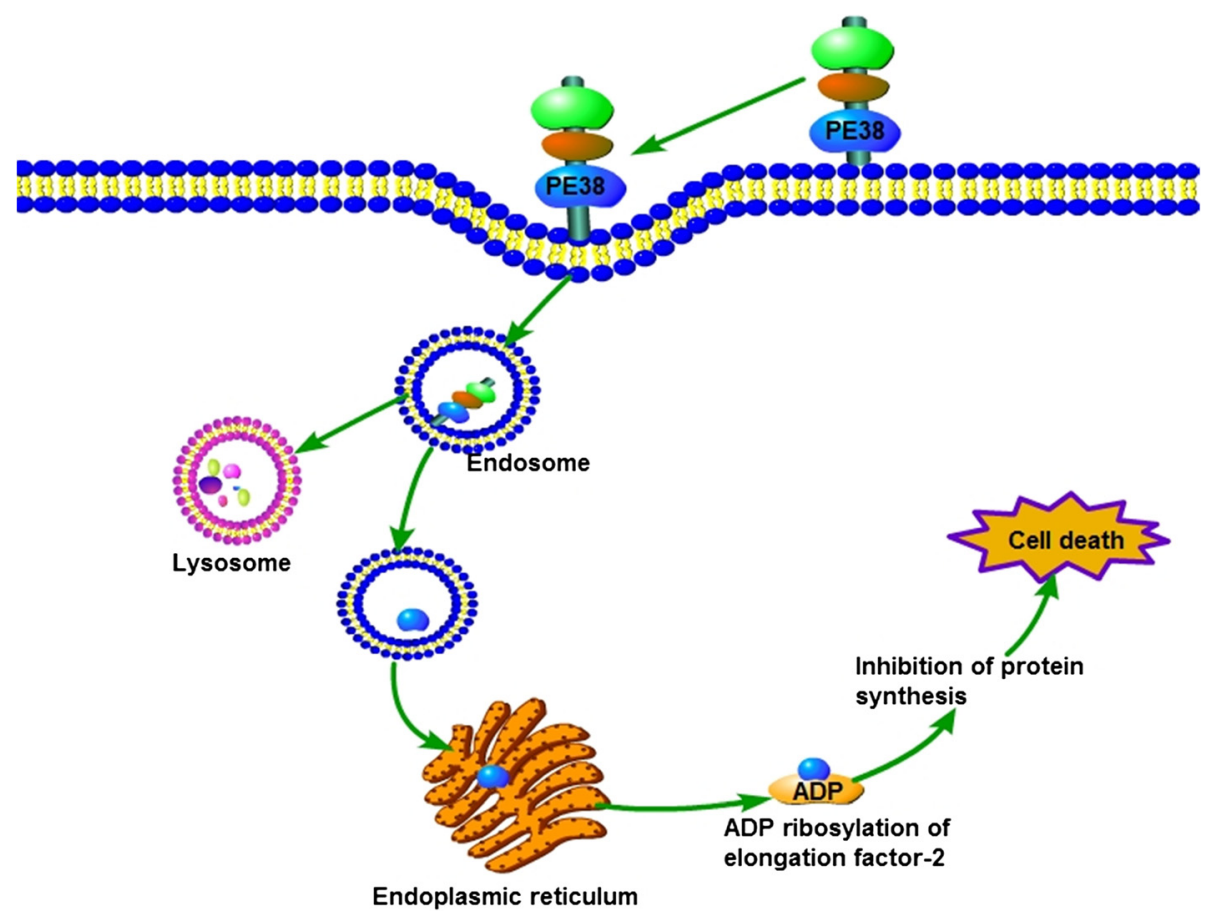

Fig. 5 The mechanism of PE38-induced cell death. The immunotoxin is internalized when it binds with its specific receptor via the endolysosomal system to the Golgi, and it is further transported to the endoplasmic reticulum. Then, it can cause ADP ribosylation and elongation factor 2 inactivation to halt protein synthesis and eventually lead to cell death

eliminate the established cancer, as some parts of the expanding tumors do not express CCR9, thereby rendering CCL25-PE38 ineffective [55].

\section{Others}

We also found that T-ALL cells can increase the expression of IL-4 after treatment with IL-2 and that IL-2 can activate the PKC and GRK2 signaling pathways to induce CCR9 internalization, thereby reducing leukemia cell infiltration and metastasis [56].

\section{Conclusions}

CCL25/CCR9, as a member of the CC chemokines and their receptors, is known to be involved in chemotactic cells, lymphocyte development, survival, proliferation, and migration. Recently, researchers have found that CCL25/CCR9 plays an important role in tumorigenesis and is mainly involved in tumor chemoresistance and metastasis, which hamper the effects of conventional surgery, radiotherapy, and chemotherapy. Therefore, CCR9 has become a potential targeted molecule for cancer therapy because it is highly expressed in various cancers (Table 1). Targeting therapy drugs can be delivered into exact positions and can then be gradually released, thus reducing drug systemic side effects with enhanced antitumor efficiency
[57]. Nevertheless, substantial work is still required, and future research efforts will provide us with a pharmacological basis of the therapeutic use of targeted therapy in cancer and a basis for the further investigation of other potential anti-CCR9 agents.

\section{Abbreviations}

CCL25: chemokine ligand 25; CCR9: chemokine receptor 9; MMPs: matrix metalloproteinases; PDK: phosphoinositide dependent kinase;

PE: Pseudomonas exotoxin A; T-ALL: T-lineage acute lymphoblastic leukemia; TECK: thymus-expressed chemokine; TNF-a: tumor necrosis factor-a.

Competing interests

The authors declare that they have no competing interests.

\section{Authors' contributions}

$Z T$ and RX performed the selection of literature and drafted the manuscript. $J X, X D$ and MX carried out figures making, KMT, PL and MW revised the language. QZ carried out the design of the review. All authors read and approved the final manuscript.

\section{Acknowledgements}

This work was supported by the National Natural Science Foundation of China (No. 81400121, 81270607, 81541027).

Received: 7 December 2015 Accepted: 21 January 2016

Published online: 16 February 2016

References

1. Weitzenfeld P, Ben-Baruch A. The chemokine system, and its CCR5 and CXCR4 receptors, as potential targets for personalized therapy in cancer Cancer Lett. 2014;352(1):36-53. 
2. Sharma S, Zhu L, Srivastava MK, Harris-White M, Huang M, Lee JM, et al. CCL21 chemokine therapy for lung cancer. Int Trends Immun. 2013;1(1):10-5.

3. Lazennec G, Richmond A. Chemokines and chemokine receptors: new insights into cancer-related inflammation. Trends Mol Med. 2010;16(3): 133-44

4. Mukaida N, Baba T. Chemokines in tumor development and progression. Exp Cell Res. 2012;318(2):95-102.

5. Sarvaiya PJ, Guo D, Ulasov I, Gabikian P, Lesniak MS. Chemokines in tumor progression and metastasis. Oncotarget. 2013;4(12):2171-85.

6. Valdivia-Silva JE, Franco-Barraza J, Silva AL, Pont GD, Soldevila G, Meza I, et al. Effect of pro-inflammatory cytokine stimulation on human breast cancer: implications of chemokine receptor expression in cancer metastasis. Cancer Lett. 2009;283(2):176-85.

7. Mirandola L, Chiriva-Internati M, Montagna D, Locatelli F, Zecca M, Ranzani $M$, et al. Notch1 regulates chemotaxis and proliferation by controlling the CC-chemokine receptors 5 and 9 in T cell acute lymphoblastic leukaemia. J Pathol. 2012;226(5):713-22.

8. Siegel R, Naishadham D, Jemal A. Cancer statistics, 2013. CA Cancer J Clin. 2013;63(1):11-30.

9. Zhang Z, Qin C, Wu Y, Su Z, Xian G, Hu B. CCR9 as a prognostic marker and therapeutic target in hepatocellular carcinoma. Oncol Rep. 2014:31(4):1629-36.

10. Koga A, Kajihara I, Yamada S, Makino K, Ichihara A, Aoi J, et al. Enhanced CCR9 expression levels in psoriatic skin are associated with poor clinical outcome to infliximab treatment. J Dermatol. 2015.

11. Singh R, Stockard CR, Grizzle WE, Lillard Jr JW, Singh S. Expression and histopathological correlation of CCR9 and CCL25 in ovarian cancer. Int J Oncol. 2011;39(2):373-81.

12. Li B, Wang Z, Zhong Y, Lan J, Li X, Lin H. CCR9-CCL25 interaction suppresses apoptosis of lung cancer cells by activating the PI3K/Akt pathway. Med Oncol. 2015;32(3):66

13. Shen X, Mailey B, Ellenhorn JD, Chu PG, Lowy AM, Kim J. CC chemokine receptor 9 enhances proliferation in pancreatic intraepithelial neoplasia and pancreatic cancer cells. Journal of gastrointestinal surgery : official journal of the Society for Surgery of the Alimentary Tract. 2009;13(11):1955-62. discussion 1962

14. Sharma PK, Singh R, Novakovic KR, Eaton JW, Grizzle WE, Singh S. CCR9 mediates PI3K/AKT-dependent antiapoptotic signals in prostate cancer cells and inhibition of CCR9-CCL25 interaction enhances the cytotoxic effects of etoposide. International journal of cancer Journal international du cancer. 2010;127(9):2020-30.

15. Johnson-Holiday C, Singh R, Johnson EL, Grizzle WE, Lillard Jr JW, Singh S. CCR9-CCL25 interactions promote cisplatin resistance in breast cancer cell through Akt activation in a PI3K-dependent and FAK-independent fashion World journal of surgical oncology. 2011;9:46.

16. Johnson EL, Singh R, Johnson-Holiday CM, Grizzle WE, Partridge EE, Lillard Jr JW, et al. CCR9 interactions support ovarian cancer cell survival and resistance to cisplatin-induced apoptosis in a PI3Kdependent and FAK-independent fashion. Journal of ovarian research. 2010;3:15

17. Qiuping Z, Jei X, Youxin J, Wei J, Chun L, Jin W, et al. CC chemokine ligand 25 enhances resistance to apoptosis in CD4+ T cells from patients with $\mathrm{T}$ cell lineage acute and chronic lymphocytic leukemia by means of Livin activation. Cancer Res. 2004:64(20):7579-87.

18. Zhang L, Xiao R, Xiong J, Leng J, Ehtisham A, Hu Y, et al. Activated ERM protein plays a critical role in drug resistance of MOLT4 cells induced by CCL25. PLoS One. 2013;8(1):e52384

19. Khandelwal N, Breinig M, Speck T, Michels T, Kreutzer C, Sorrentino A, et al. A high-throughput RNAi screen for detection of immune-checkpoint molecules that mediate tumor resistance to cytotoxic T lymphocytes. EMBO Mol Med. 2015;7(4):450-63.

20. Lee S, Heinrich EL, Li L, Lu J, Choi AH, Levy RA, et al. CCR9-mediated signaling through beta-catenin and identification of a novel CCR9 antagonist. Mol Oncol. 2015;9(8):1599-611.

21. Johnson EL, Singh R, Singh S, Johnson-Holiday CM, Grizzle WE, Partridge EE, et al. CCL25-CCR9 interaction modulates ovarian cancer cell migration, metalloproteinase expression, and invasion. World journal of surgical oncology. 2010;8:62.

22. Singh S, Singh UP, Stiles JK, Grizzle WE, Lillard Jr JW. Expression and functional role of CCR9 in prostate cancer cell migration and invasion. Clinical cancer research : an official journal of the American Association for Cancer Research. 2004;10(24):8743-50
23. Gupta P, Sharma PK, Mir H, Singh R, Singh N, Kloecker GH, et al. CCR9/ CCL25 expression in non-small cell lung cancer correlates with aggressive disease and mediates key steps of metastasis. Oncotarget. 2014.

24. Wang Y, Yu J, Luo X, Wang X, Li M, Wang L, et al. Abnormal regulation of chemokine TECK and its receptor CCR9 in the endometriotic milieu is involved in pathogenesis of endometriosis by way of enhancing invasiveness of endometrial stromal cells. Cellular \& molecular immunology. 2010;7(1):51-60

25. Qiuping Z, Qun L, Chunsong H, Xiaolian Z, Baojun H, Mingzhen Y, et al. Selectively increased expression and functions of chemokine receptor CCR9 on CD4+ T cells from patients with T-cell lineage acute lymphocytic leukemia. Cancer Res. 2003;63(19):6469-77.

26. Zhou B, Leng J, Hu M, Zhang L, Wang Z, Liu D, et al. Ezrin is a key molecule in the metastasis of MOLT4 cells induced by CCL25/CCR9. Leuk Res. 2010; 34(6):769-76.

27. Zhang L, Yu B, Hu M, Wang Z, Liu D, Tong X, et al. Role of Rho-ROCK signaling in MOLT4 cells metastasis induced by CCL25. Leuk Res. 2011:35(1):103-9.

28. Heinrich EL, Arrington AK, Ko ME, Luu C, Lee W, Lu J, et al. Paracrine activation of chemokine receptor CCR9 enhances the invasiveness of pancreatic cancer cells. Cancer microenvironment: official journal of the International Cancer Microenvironment Society. 2013;6(3):241-5.

29. Seidl H, Richtig E, Tilz H, Stefan M, Schmidbauer U, Asslaber M, et al. Profiles of chemokine receptors in melanocytic lesions: de novo expression of CXCR6 in melanoma. Hum Pathol. 2007;38(5):768-80.

30. Amersi FF, Terando AM, Goto Y, Scolyer RA, Thompson JF, Tran AN, et al. Activation of CCR9/CCL25 in cutaneous melanoma mediates preferential metastasis to the small intestine. Clinical cancer research: an official journal of the American Association for Cancer Research. 2008; 14(3):638-45.

31. Letsch A, Keilholz U, Schadendorf D, Assfalg G, Asemissen AM, Thiel E, et al. Functional CCR9 expression is associated with small intestinal metastasis. The Journal of investigative dermatology. 2004;122(3):685-90.

32. Nagakubo D, Jin Z, Hieshima K, Nakayama T, Shirakawa AK, Tanaka Y, et al. Expression of CCR9 in HTLV-1+ T cells and ATL cells expressing Tax. International journal of cancer Journal international du cancer. 2007:120(7):1591-7.

33. Miething C, Scuoppo C, Bosbach B, Appelmann I, Nakitandwe J, Ma J, et al. PTEN action in leukaemia dictated by the tissue microenvironment. Nature. 2014:510(7505):402-6.

34. Breton CS, Nahimana A, Aubry D, Macoin J, Moretti P, Bertschinger M, et al. A novel anti-CD19 monoclonal antibody (GBR 401) with high killing activity against B cell malignancies. J Hematol Oncol. 2014;7:33.

35. Wu J, Fu J, Zhang M, Liu D. Blinatumomab: a bispecific T cell engager (BiTE) antibody against CD19/CD3 for refractory acute lymphoid leukemia. J Hematol Oncol. 2015;8:104.

36. Fan D, Li W, Yang Y, Zhang $X$, Zhang $Q$, Yan $Y$, et al. Redirection of CD4+ and CD8+ T lymphocytes via an anti-CD3 $x$ anti-CD19 bi-specific antibody combined with cytosine arabinoside and the efficient lysis of patientderived B-ALL cells. J Hematol Oncol. 2015:8(1):108.

37. Ehrlich D, Wang B, Lu W, Dowling P, Yuan R. Intratumoral anti-HuD immunotoxin therapy for small cell lung cancer and neuroblastoma. J Hematol Oncol. 2014;7:91.

38. Kuhne MR, Mulvey T, Belanger B, Chen S, Pan C, Chong C, et al. BMS936564/MDX-1338: a fully human anti-CXCR4 antibody induces apoptosis in vitro and shows antitumor activity in vivo in hematologic malignancies. Clinical cancer research: an official journal of the American Association for Cancer Research. 2013;19(2):357-66.

39. Panjideh H, Muller G, Koch M, Wilde F, Scheu S, Moldenhauer G, et al. Immunotherapy of B-cell non-Hodgkin lymphoma by targeting the chemokine receptor CXCR5 in a preclinical mouse model. International journal of cancer Journal international du cancer. 2014; 135(11):2623-32

40. Ishii T, Ishida T, Utsunomiya A, Inagaki A, Yano H, Komatsu $H$, et al. Defucosylated humanized anti-CCR4 monoclonal antibody KW-0761 as a novel immunotherapeutic agent for adult T-cell leukemia/lymphoma. Clinical cancer research: an official journal of the American Association for Cancer Research. 2010;16(5):1520-31.

41. Somovilla-Crespo B, Alfonso-Perez M, Cuesta-Mateos C, Carballo-de Dios C, Beltran AE, Terron F, et al. Anti-CCR7 therapy exerts a potent anti-tumor activity in a xenograft model of human mantle cell lymphoma. J Hematol Oncol. 2013;6:89. 
42. Chamorro S, Vela M, Franco-Villanueva A, Carramolino L, Gutierrez J, Gomez $L$, et al. Antitumor effects of a monoclonal antibody to human CCR9 in leukemia cell xenografts. mAbs. 2014;6(4):1000-12.

43. Antignani A, Fitzgerald D. Immunotoxins: the role of the toxin. Toxins. 2013; 5(8):1486-502.

44. Mazor R, Eberle JA, Hu X, Vassall AN, Onda M, Beers R, et al. Recombinant immunotoxin for cancer treatment with low immunogenicity by identification and silencing of human T-cell epitopes. Proc Natl Acad Sci U S A. 2014;111(23):8571-6.

45. Fan G, Wang Z, Hao M, Li J. Bispecific antibodies and their applications. J Hematol Oncol. 2015;8(1):130.

46. Suresh T, Lee LX, Joshi J, Barta SK. New antibody approaches to lymphoma therapy. J Hematol Oncol. 2014;7:58.

47. Fonseca NA, Gregorio AC, Valerio-Fernandes A, Simoes S, Moreira JN. Bridging cancer biology and the patients' needs with nanotechnologybased approaches. Cancer Treat Rev. 2014;40(5):626-35.

48. Unger E, Porter T, Lindner J, Grayburn P. Cardiovascular drug delivery with ultrasound and microbubbles. Adv Drug Deliv Rev. 2014;72:110-26.

49. Yu Y, Zhang M, Zhang $X$, Cai Q, Hong S, Jiang W, et al. Synergistic effects of combined platelet-activating factor receptor and epidermal growth factor receptor targeting in ovarian cancer cells. J Hematol Oncol. 2014;7:39.

50. Liu W, Onda M, Lee B, Kreitman RJ, Hassan R, Xiang L, et al. Recombinant immunotoxin engineered for low immunogenicity and antigenicity by identifying and silencing human B-cell epitopes. Proc Natl Acad Sci U S A. 2012;109(29):11782-7.

51. Smith AD, Roda D, Yap TA. Strategies for modern biomarker and drug development in oncology. J Hematol Oncol. 2014;7:70.

52. Bera TK, Onda M, Kreitman RJ, Pastan I. An improved recombinant Fabimmunotoxin targeting CD22 expressing malignancies. Leuk Res. 2014; 38(10):1224-9.

53. Weldon JE, Xiang L, Zhang J, Beers R, Walker DA, Onda M, et al. A recombinant immunotoxin against the tumor-associated antigen mesothelin reengineered for high activity, low off-target toxicity, and reduced antigenicity. Mol Cancer Ther. 2013;12(1):48-57.

54. Wayne AS, Fitzgerald DJ, Kreitman RJ, Pastan I. Immunotoxins for leukemia. Blood. 2014;123(16):2470-7.

55. Hu Y, Zhang L, Wu R, Han R, Jia Y, Jiang Z, et al. Specific killing of CCR9 high-expressing acute T lymphocytic leukemia cells by CCL25 fused with PE38 toxin. Leuk Res. 2011;35(9):1254-60.

56. Tong X, Zhang L, Zhang L, Hu M, Leng J, Yu B, et al. The mechanism of chemokine receptor 9 internalization triggered by interleukin 2 and interleukin 4. Cellular \& molecular immunology. 2009:6(3):181-9.

57. Rizvi NA, Hellmann MD, Snyder A, Kvistborg P, Makarov V, Havel JJ, et al. Cancer immunology. Mutational landscape determines sensitivity to PD-1 blockade in non-small cell lung cancer. Science. 2015;348(6230):124-8.

58. Fusi A, Liu Z, Kummerlen V, Nonnemacher A, Jeske J, Keilholz U. Expression of chemokine receptors on circulating tumor cells in patients with solid tumors. J Transl Med. 2012;10:52.

59. Kuhnelt-Leddihn L, Muller H, Eisendle K, Zelger B, Weinlich G. Overexpression of the chemokine receptors CXCR4, CCR7, CCR9, and CCR10 in human primary cutaneous melanoma: a potential prognostic value for CCR7 and CCR10? Arch Dermatol Res. 2012;304(3):185-93.

60. Rehm A, Anagnostopoulos I, Gerlach K, Broemer M, Scheidereit C, Johrens K, et al. Identification of a chemokine receptor profile characteristic for mediastinal large B-cell lymphoma. International journal of cancer Journal international du cancer. 2009;125(10):2367-74.

61. Deutsch AJ, Steinbauer E, Hofmann NA, Strunk D, Gerlza T, Beham-Schmid $C$, et al. Chemokine receptors in gastric MALT lymphoma: loss of CXCR4 and upregulation of CXCR7 is associated with progression to diffuse large B-cell lymphoma. Modern pathology : an official journal of the United States and Canadian Academy of Pathology, Inc. 2013;26(2):182-94.

62. Wu W, Doan N, Said J, Karunasiri D, Pullarkat ST. Strong expression of chemokine receptor CCR9 in diffuse large B-cell lymphoma and follicular lymphoma strongly correlates with gastrointestinal involvement. Hum Pathol. 2014;45(7):1451-8.

63. Fan J, Zhang L, Wang Q, Lin $\mathrm{H}$. Chemokine receptor 9 high-expression involved in the migration and invasion of the non-small-cell lung cancer cells. Asian Biomedicine. 2011;5(1):7.

64. Johnson-Holiday C, Singh R, Johnson E, Singh S, Stockard CR, Grizzle WE, et al. CCL25 mediates migration, invasion and matrix metalloproteinase expression by breast cancer cells in a CCR9-dependent fashion. Int J Oncol. 2011;38(5):1279-85.

65. Chen HJ, Edwards R, Tucci S, Bu P, Milsom J, Lee S, et al. Chemokine 25induced signaling suppresses colon cancer invasion and metastasis. J Clin Invest. 2012;122(9):3184-96.

66. Ye LF, Huang J, Zhang LP, Chen Z. Intracellular expression profile and clinical significance of the CCR9-CCL25 chemokine receptor complex in nasopharyngeal carcinoma. J Laryngol Otol. 2015;129(10):1013-9.

\section{Submit your next manuscript to BioMed Central and we will help you at every step:}

- We accept pre-submission inquiries

- Our selector tool helps you to find the most relevant journal

- We provide round the clock customer support

- Convenient online submission

- Thorough peer review

- Inclusion in PubMed and all major indexing services

- Maximum visibility for your research

Submit your manuscript at www.biomedcentral.com/submit
C Biomed Central 